\section{Safer technique for passing abdominal trochar}

Thomas H.S. Fysh, Douglas Ferguson

Department of Surgery, Royal Devon and Exeter NHS Foundation Trust, Wonford, Exeter, UK

Many closed surgical drainage systems are delivered through the abdominal wall with a trochar. Sometimes this manoeuvre requires significant force, potentially compromising control and causing injury, either to the patient or to operating theatre personnel.

By using the finger holes of pair of closed Mayo scissors to provide counter-pressure against the abdominal wall and with the trochar held still on the other side, the drain can be easily and safely passed.

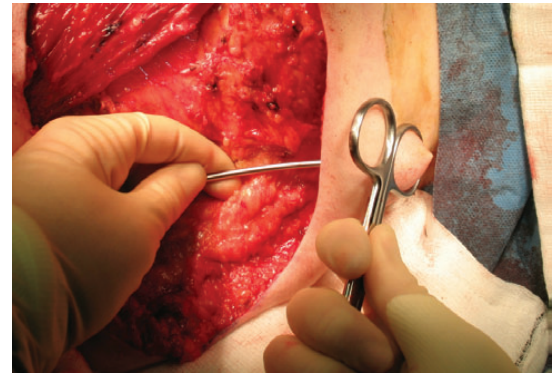

Figure 1. Trochar being passed safely.
Correspondence: Thomas H.S. Fysh, Department of Surgery, Royal Devon and Exeter NHS Foundation Trust, Barrack Road, Wonford, Exeter EX2 5DW, United Kingdom.

Tel. +44.0.1392 411611.

E-mail: tomfysh@doctors.net.uk

Key words: trochar, drainage technique, safety.

Contributions: DF, technique conceiving; TF, photograph performing and manuscript writing.

Conflict of interest: the authors report no conflicts of interest.

Received for publication: 15 June 2011. Accepted for publication: 30 June 2011.

This work is licensed under a Creative Commons Attribution NonCommercial 3.0 License (CC BYNC 3.0).

() Copyright T.H.S. Fysh and D.Ferguson, 2011 Licensee PAGEPress, Italy

Surgical Techniques Development 2011; 1:e5 doi:10.4081/std.2011.e5 